\title{
Combustion characteristics in an iron ore sintering bed-evaluation of fuel substitution
}

\author{
Won Yang ${ }^{\mathrm{a}, 1}$, Sangmin Choi ${ }^{\mathrm{a}, *}$, Eung Soo Choi ${ }^{\mathrm{b}}$, Deog Won Ri ${ }^{\mathrm{b}}$, \\ Sungman Kim $^{\mathrm{b}}$

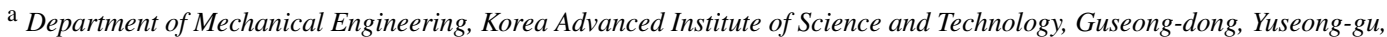 \\ Daejeon, South Korea \\ b POSCO, Technical Research Labs, Goedong-dong, Nam-gu, Pohang, Gyeongbuk 790-785, South Korea
}

Received 14 May 2005; received in revised form 15 December 2005; accepted 12 January 2006

Available online 9 March 2006

\begin{abstract}
In an iron ore sintering bed, combustion of solid fuel supplies heat needed for sintering of fine particles and determines the quality of the sintered ores and the productivity of the process. Coke has been widely used as an ideal fuel for this process, but recent attempts to partially replace coke with a less expensive fuel have been considered effective in the real applications. This paper reports simulation results of mathematical modeling of bed combustion as well as experimental observation from scale-downed pot tests. Combustion characteristics of the solid fuel bed are also described and fuel substitution from coke to anthracite coal is evaluated. A numerical model of the 1-D unsteady level considers the processes in the bed of particles: drying, devolatilization, char reactions, gaseous reactions, heat transfer, and geometrical changes of the bed material. The model can treat the solid material as multiple solid phases whose contents include fine particles of iron ore, limestone, coke, and coal. Quantitative parameters are newly defined for characterization of the bed combustion. These include flame front speed, sintering time, duration time in the combustion zone, combustion zone thickness, melting zone thickness, and maximum temperature. Relationships between these parameters and the mechanism of combustion propagation are also investigated. The results show quantitatively that temperature profiles, combustion propagation, and thickness of the combustion zone in the bed are dominated by combustion-related operating parameters. This description is applied to case studies for various coke contents, air supply rates, and fuel characteristics. It is shown that the different reactivity of anthracite in comparison with coke can significantly affect the bed combustion in terms of combustion propagation and the quality of the sintered ores in the upper part of the bed.
\end{abstract}

( 2006 The Combustion Institute. Published by Elsevier Inc. All rights reserved.

Keywords: Coke; Anthracite; Combustion characteristics; Iron ore sintering; Sintering pot

* Corresponding author.

E-mail address: smchoi@kaist.ac.kr (S. Choi).

1 Current address: Industrial Equipment Team, Korea Institute of Industrial Technology, 35-3 Hongchon-Ri, Ipchang-Myun, Chonan-Si, Chungnam 330-825, South Korea.

\section{Introduction}

Coal combustion in a mixed bed of solid material is commonly utilized in ironmaking processes such as iron ore sintering and blast furnace processes. Typically, coal is supplied as coke, which is produced by coking coal in an oven. At present, a limited amount 


\section{Nomenclature}

$\begin{array}{ll}\text { CZT } & \text { Combustion zone thickness, cm } \\ C_{\mathrm{p}} & \text { Specific heat, } \mathrm{J} / \mathrm{kg} \mathrm{K} \\ \text { DTCZ } & \text { Duration time in combustion zone, } \mathrm{s} \\ \mathrm{FFS} & \text { Flame front speed, } \mathrm{cm} / \mathrm{min} \\ f_{\mathrm{V}} & \text { Volume fraction } \\ h & \text { Convective heat transfer coefficient, } \\ & \mathrm{W} / \mathrm{m}^{2} \mathrm{~K} \\ h & \text { Thermal enthalpy per unit volume, } \mathrm{J} / \mathrm{m}^{3} \\ k & \text { Thermal conductivity, } \mathrm{W} / \mathrm{m} \mathrm{K} \\ \dot{M}_{\mathrm{g}} & \text { Volumetric mass generation rate by } \\ & \text { gaseous reaction, } \mathrm{kg} / \mathrm{m}^{3} \mathrm{~s} \\ \dot{M}_{\mathrm{S}} & \text { Volumetric mass generation rate by } \\ & \text { solid-gas reaction, } \mathrm{kg} / \mathrm{m}^{3} \mathrm{~s} \\ \mathrm{MaxT} & \text { Maximum temperature } \\ \mathrm{MZT} & \text { Melting temperature } \\ q & \text { Heat per unit volume, } \mathrm{W} / \mathrm{m}^{2} \\ S & \text { General source term } \\ \mathrm{ST} & \text { Sintering time } \\ T & \text { Temperature, } \mathrm{K} \\ t & \text { Time, } \mathrm{s}\end{array}$

$\begin{array}{ll}v & \text { Velocity, } \mathrm{m} / \mathrm{s} \\ Y & \text { Mass fraction } \\ y & \text { Vertical distance, } \mathrm{m} \\ y & \text { Fraction of heat absorbed by solid } \\ \Gamma & \text { General diffusion coefficient } \\ \Delta H & \text { Reaction heat, } \mathrm{J} / \mathrm{kg} \\ \Delta P & \text { Pressure difference, } \mathrm{Pa} \\ \rho & \text { Density, } \mathrm{kg} / \mathrm{m}^{3} \\ \phi & \text { General scalar quantity }\end{array}$

\section{Subscripts}

$\begin{array}{ll}\text { conv } & \text { Convection } \\ \mathrm{g} & \text { Gas } \\ I, J & \text { Index of solid phase } \\ k & \text { Solid component or gas species } \\ r_{\mathrm{s}} & \text { Solid-gas reaction } \\ r_{\mathrm{g}} & \text { Gaseous reaction } \\ \mathrm{rad} & \text { Radiation } \\ \mathrm{s} & \text { Solid }\end{array}$

of coke is being replaced with less expensive coal. However, coke is still widely used because of its unique combustion properties, as well as its mechanical and structural properties.

Sintering is a preprocess to form iron ore powder (typically less than $1 \mathrm{~mm}$ in size) into aggregates of porous chunks of iron ore (typically larger than a few centimeters, with physical properties suitable for operation in a blast furnace). Coal occupies at most $\sim 4 \%$ of solid material in the form of coke fine. Coke combustion provides iron ores with the energy required for sintering. Fig. 1 shows a schematic diagram of the sintering process. Various kinds of iron ores, coke, and limestone are mixed with water in a rotating drum and form pseudo-particles. They are fed into a sintering bed having a length of $\sim 100 \mathrm{~m}$ and a height of $\sim 0.6 \mathrm{~m}$ and move along a grate at a constant speed. The top of the bed is heated and ignited by a gas burner during $\sim 100 \mathrm{~s}$. Once ignited, coke combustion is sustained for $25-30 \mathrm{~min}$ to the end of the process without any external heat source. Surface melting and sintering occur in the high-temperature region. Combustion air is supplied by a suction fan, and the air exchanges heat with hot agglomerated ores over the combustion zone. After passing through the combustion and sintering zone, the hot gas is used for evaporation of the raw mix and transfers the steam downstream. The steam is condensed in the cold region of the bed in the lower part. These coal combustion characteristics in the bed significantly influence the quality and productivity of sintered ore. Thus, it is important to control the combustion-related parameters, which should be set by investigation of coal combustion characteristics in the iron ore bed.

If the transfer phenomena along the directions of grate length and width are neglected, an iron ore sintering process can be considered as 1-D unsteady (along the direction of bed height) when the time axis can be transformed into length by multiplication of the traveling speed by the time, which is usually constant during the whole process. For this reason, many researchers have numerically simulated the sintering process using 1-D unsteady partial differential equations [1-8] and have performed lab-scale experiments known as "sintering pot tests" $[1-4,6]$. Results of the tests can provide designers and operators with useful information on combustion conditions, flue gas compositions, and quality of the product, which can be used for optimization of the whole sintering process. This approach has been reported in the field of combustion modeling of solid fuel beds such as waste incinerators [8-11] and coal/biomass combustion/gasification systems [12-18]. Most previous works treated the solid material as a single solid phase. However, this approach does not appear to be appropriate in the combustion modeling of a sintering bed, in which various kinds of solid material are uniformly mixed and the size of each solid material can significantly affect the combustion conditions and productivity of the process. Therefore, some researchers proposed a 1-D unsteady model [7] of solid bed combustion that can treat solid material as mul- 


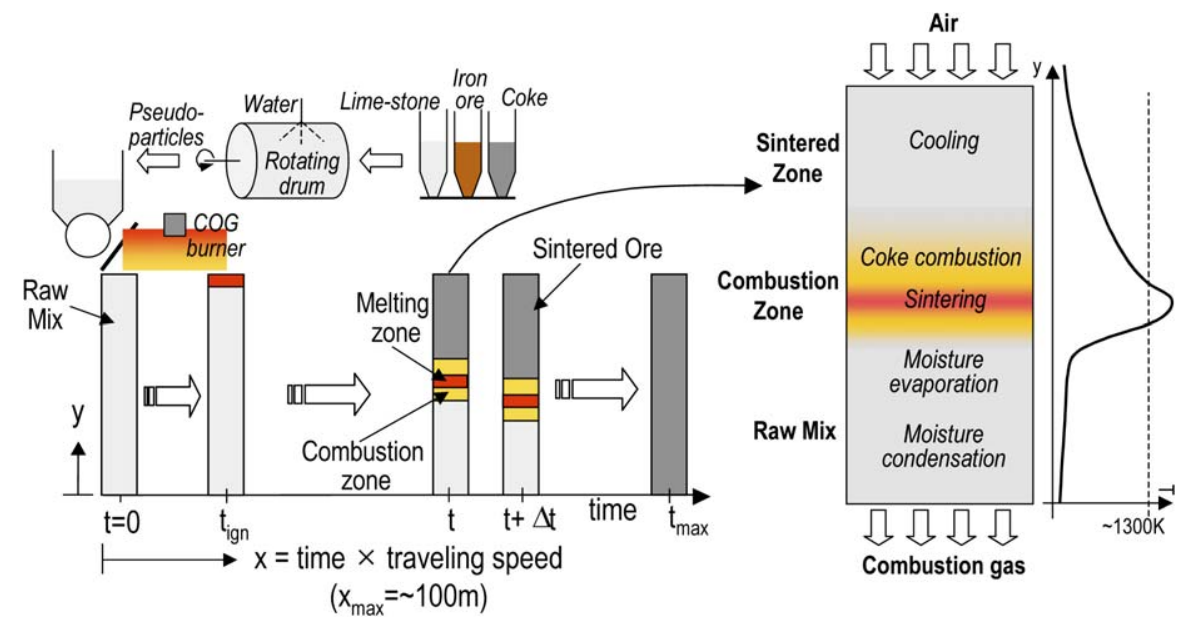

Fig. 1. Schematic diagram of sintering process in the ironmaking process.

tiple solid phases. Thus, different fuel characteristics such as particle size and composition can be effectively simulated. However, a more systematic, quantitative analysis is needed for interpretation and evaluation of the results for practical design and operation. In particular, combustion characteristics should be described quantitatively for evaluation of the operating conditions of the process. Flame front speed (FFS) is considered an important quantitative parameter for characterization of the bed combustion [7,9]. It can describe the propagation speed of the combustion zone, which represents the productivity of the sintered ores. However, features of the combustion/reaction zone itself are also important with respect to the quality and characteristics of the products. For this reason, some additional parameters need to be introduced for characterization of the combustion zone, and numerical study would extend the applicability of the available parameters.

One of the most important issues in the ironmaking process, including sintering, is fuel substitution for coke, which has traditionally been used. Coke derived from softening coal is more reactive, but is considerably more expensive. For this reason, coke has been replaced in part with powdered anthracite as a low-cost fuel. However, the difference in reactivity of anthracite must be evaluated to avoid undesirable effects in terms of productivity and quality of the sintered ore.

In this study, a systematic method for analyzing the computational and experimental results of the iron ore sintering process is proposed. Experiments and numerical test cases are designed to simulate sintering pot tests and fuel contents and air supply are parametrically studied. Some quantitative parameters of bed combustion are introduced and the test results are dis- cussed in conjunction with these parameters. Quantitative discussion is designed to show the effects of fuel replacement of coke with coal.

\section{Characterization of bed combustion}

The key features of solid bed combustion that distinguish it from the combustion characteristics of a single fuel particle are combustion propagation through the bed and temperature and thickness of the combustion zone itself. These features are closely related to combustion conditions such as air/fuel ratio and external heat supply, as well as the fuel characteristics of a single particle. In this study, combustion characteristics of an iron ore sintering bed are described in terms of temperature and solid component distribution within the bed.

Fig. 2 shows a conceptual diagram of the combustion characteristics in an iron ore sintering bed in terms of temperature distribution. Definitions of the quantitative parameters are also introduced for characterization of solid bed combustion. Combustion/sintering is initiated from the top of the bed. As the combustion zone propagates downward, its thickness increases by accumulation of combustion heat. The solid bed is divided into four regions by temperature and mass fraction of char within the bed: a raw mix zone, a combustion zone, a melting zone, and a completely sintered zone. The combustion zone is defined as the area in which the temperature of the solid phase, which includes coal char, is high enough to obtain oxidation and char mass fraction is sufficiently larger than a small value $\varepsilon$. This means that the char combustion occurs in the zone where the solid temperature and $\varepsilon$ are above $1000 \mathrm{~K}$ and $10^{-5}$. Combustion characteristics in an iron ore sintering bed can 


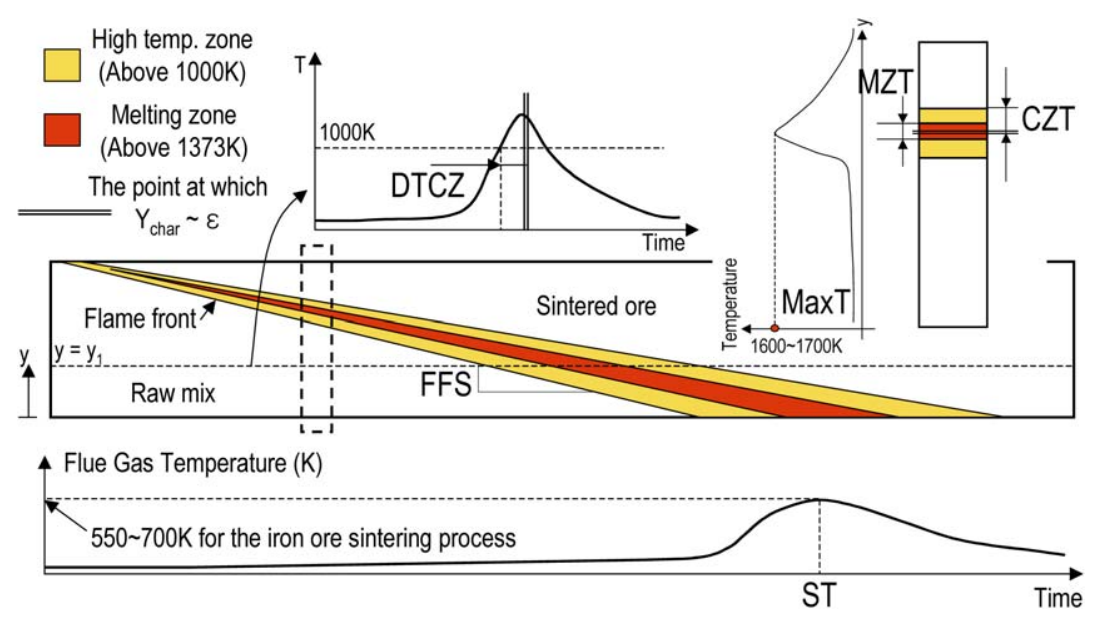

Fig. 2. Characterization of bed combustion in an iron ore sintering bed (FFS: flame front speed, ST: sintering time, DTCZ: duration time in the combustion zone, CZT: combustion zone thickness, MZT: melting zone thickness, MaxT: maximum temperature).

be significantly affected by the melting of iron ores, which influences the bed permeability and thereby disturbs airflow. Consequently, the amount of iron ore melting should be controlled to maintain appropriate combustion conditions and to produce sintered ores of high quality. The melting zone is defined as the region in which iron ore melting occurs: In this study, iron ore undergoes melting when the solid temperature is above $1373 \mathrm{~K}$ [7]. When char combustion is completed and the temperature is above the melting temperature, which implies that the zone is located in the upper part of the melting zone, the hot bed is quenched by inlet air. The flame front is the boundary between the combustion zone and the raw mix.

Based on this division of the solid bed, quantitative parameters are defined to characterize the solid bed combustion. Flame front speed (FFS) was previously introduced [7,9] to express the propagation speed of the combustion zone in the solid fuel bed. Sintering time (ST) is also used to express the propagation speed. Definitions of these parameters are given in Table 1. FFS is defined as the distance between two points along the vertical axis in the bed over the time consumed for propagation. These two points can be arbitrarily selected. The propagation time is defined as the time consumed to reach $1000 \mathrm{~K}$ between the two points. The FFS is mainly influenced by the char combustion rate and parameters of heat transfer and thermal diffusion within the bed. ST is defined as the elapsed time until the flue gas temperature reaches a maximum, which means that coke combustion is nearly completed, as shown in Fig. 2. It is inversely proportional to the flame front speed. ST is well known in the field of ironmaking process as a key parameter of productivity in the sintering process. The two parameters, i.e., the FFS and the ST, can serve as indices of combustion propagation characteristics for a single case, since they have one representative value for the whole process. Furthermore, they can be obtained by experiment and can be used as parameters for validation of the numerical model. More detailed information on the combustion propagation mechanism related to various modes of heat generation and transfer can be obtained through calculation of the heat balance terms.

The above parameters cannot, however, adequately describe all combustion conditions in the sintering bed, since they consider only the propagation of the combustion zone, but not the characteristics of the combustion zone itself, even though the characteristics can seriously influence the quality of the product from the sintering process. Therefore, in addition to FFS and ST, new parameters are introduced to describe the characteristics of the combustion zone itself: duration time in the combustion zone (DTCZ), combustion zone thickness (CZT), melting zone thickness (MZT), and maximum temperature (MaxT). These parameters can be determined from the simulation model. CZT and MZT are defined as the thickness of the combustion zone and melting zone, respectively. They can vary with time and tend to increase as the process proceeds [7]. Since the melting zone is not necessarily included in the combustion zone, MZT can be larger or smaller than CZT. DTCZ is defined as the retention time above the initiation temperature of char combustion (assumed to be $1000 \mathrm{~K}$ in this study) when the mass fraction of char content is above $\varepsilon$ (considered to be $10^{-5}$ in this study), which is a function of time and location in the bed. These parameters can be utilized to account for the amount of combustion heat and the degree of heat concentration in the bed. The maximum temperature 
Table 1

Definition of the parameters for characterization of bed combustion

\begin{tabular}{|c|c|c|}
\hline Parameters & Definition & Obtained by \\
\hline \multirow[t]{2}{*}{ Flame front speed (FFS) } & Distance between two points & \multirow[t]{2}{*}{ Measurement and computation } \\
\hline & $\overline{\text { Time consumed for propagation }}$ & \\
\hline Sintering time (ST) & $\begin{array}{l}\text { Elapsed time until the flue gas temperature } \\
\text { indicates a maximum }\end{array}$ & Measurement and computation \\
\hline $\begin{array}{l}\text { Duration time in combustion zone } \\
\text { (DTCZ) }\end{array}$ & $\begin{array}{l}\text { Retention time above the initiation tempera- } \\
\text { ture of char combustion }\end{array}$ & Computation \\
\hline Combustion zone thickness (CZT) & $\begin{array}{l}\text { Thickness of the zone whose solid tempera- } \\
\text { ture is greater than the initiation of char com- } \\
\text { bustion }\end{array}$ & Computation \\
\hline Melting zone thickness (MZT) & $\begin{array}{l}\text { Thickness of the zone where the solid tem- } \\
\text { perature is higher than the initiation of iron } \\
\text { ore melting }\end{array}$ & Computation \\
\hline Maximum temperature (MaxT) & $\begin{array}{l}\text { Maximum temperature of the solid material } \\
\text { at a given time }\end{array}$ & Computation \\
\hline
\end{tabular}

is defined as the highest temperature of the solid material at a given time. Sintering of the particles would require a high temperature, but this should be evaluated carefully with other parameters. The parameters related to the characteristics of the combustion zone are significantly affected by the fuel characteristics related to ignition, reactivity, and combustion time. If a fuel has low reactivity and long combustion time, CZT and DTCZ will be increased. However, the CZT and the DTCZ are also affected by the combustion conditions, such as air/fuel ratio, since the combustion time is directly influenced by the air supply.

\section{Experiments}

Fig. 3 shows a schematic diagram of the sintering pot test rig. The bed has a diameter of $205 \mathrm{~mm}$ and a height of $600 \mathrm{~mm}$. R-type thermocouples are installed along the axial direction of the bed: $y=$ $0.49 \mathrm{~m}$ (the upper part of the bed), $y=0.30 \mathrm{~m}$ (center), and $y=0.11 \mathrm{~m}$ (the lower part of the bed). Thus, the numerator of Eq. (1) in Table 1 is defined as the distance between the locations $y=0.49 \mathrm{~m}$ and $y=0.11 \mathrm{~m}$. Flue gas temperature is measured by a K-type thermocouple installed in the wind box. Hearth ores of diameter $10 \mathrm{~mm}$ are installed at the bottom of the pot to improve gas permeability. The assembly of pseudo-particles for the experiment follows the procedure shown in Fig. 1. Iron ores, coke, limestone, and other additives are mixed with water in the rolling chamber, which produces various sizes of pseudo-particles. Iron ores consist of many kinds of ores such as hematite, magnetite, and limonite of various origins. For measurement of particle diameter, the particles are frozen by liquid nitrogen injection and the mass fractions for each range of specific diameter

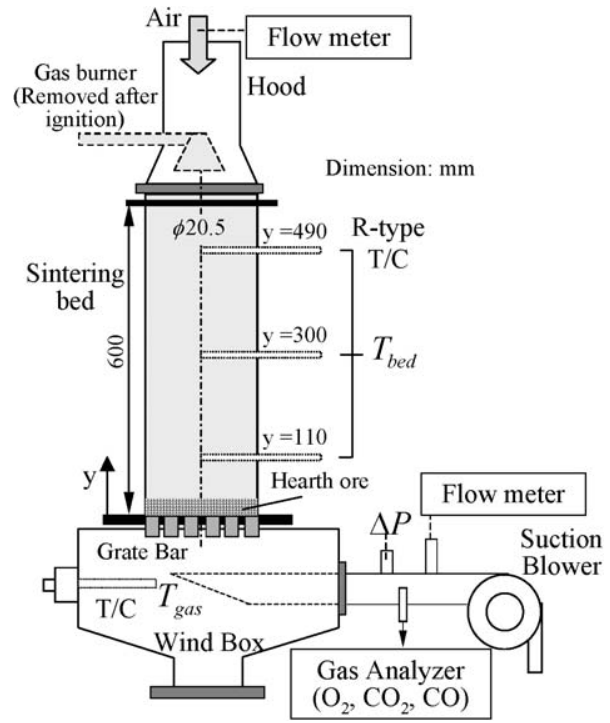

Fig. 3. Schematic diagram and dimensions of the sintering pot.

are obtained by a series of sieves (7.9, 5.0, 2.8, 2.0, and $1.0 \mathrm{~mm}$ ). Table 2 shows the distributions of the diameters of the pseudo-particles. Note that the massaveraged value of the particle sizes is $3.2 \mathrm{~mm}$.

After the selected amount of raw material, $35 \mathrm{~kg}$ in this experiment, is fed into the pot, the bed is exposed to the LPG burner for $90 \mathrm{~s}$ and is allowed to ignite. The pressure difference of the suction fan is set at $9810 \mathrm{~Pa}(1000 \mathrm{~mm} \mathrm{Aq})$ during ignition and at $14,715 \mathrm{~Pa}(1500 \mathrm{~mm} \mathrm{Aq})$ afterward. Gas inlet velocity, flow rates, and flue gas compositions including $\mathrm{O}_{2}, \mathrm{CO}_{2}$, and $\mathrm{CO}$ are continuously measured. Mass conservation of the gas is checked by measuring the inlet velocities and the volumetric gas flow rate at the 
Table 2

Distribution of the pseudo particle sizes

\begin{tabular}{llllllll}
\hline & \multicolumn{2}{l}{ Diameter $(\mathrm{mm})$} & & & Average \\
\cline { 2 - 9 } & +7.9 & +5.0 & +2.8 & +2.0 & +1.0 & -1.0 & \\
\hline Mass fraction & 0.0753 & 0.1151 & 0.2277 & 0.1700 & 0.2417 & 0.1700 & $3.2 \mathrm{~mm}$ \\
\hline
\end{tabular}

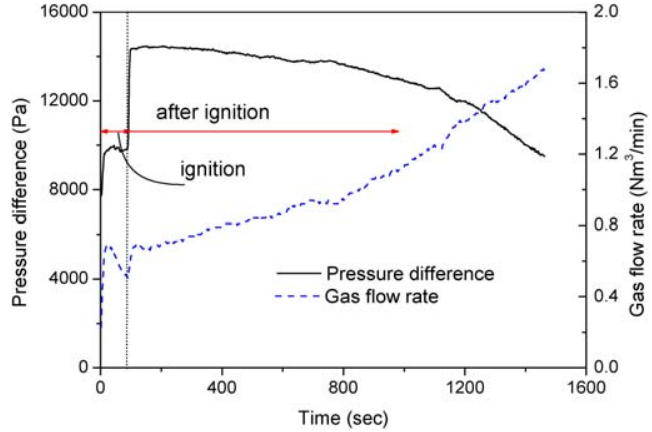

Fig. 4. Typical trends of the pressure difference and gas flow rate in the sintering pot [7].

outlet. Fig. 4 shows typical profiles of the pressure difference and gas flow rate measured in this study. The initial pressure drop represents the amount of combustion air. After the initial value is set, the suction pressure varies as coal combustion progresses, while the rotation speed of the fan is held constant.

\section{Model study}

A 1-D unsteady model was constructed to investigate the effects of phenomena in detail and to obtain the values of quantitative parameters related to the coal combustion characteristics in an iron ore sintering bed. Table 3 outlines the scope of the model. Solid material is modeled as homogeneous porous media and multiple phases, which enables the consideration of different fuel characteristics and various particle diameters. Therefore, governing equations can be described as a system of partial differential equations with the general form

$$
\frac{\partial\left(\rho f_{\mathrm{v}} \phi\right)}{\partial t}+\frac{\partial(\rho \phi v)}{\partial y}=\frac{\partial}{\partial y}\left(\Gamma_{\text {eff }} \frac{\partial \phi}{\partial y}\right)+S_{\phi} .
$$

Mass, energy, and species conservation equations for each phase, as summarized in Table 4, were solved. Submodels of solid-gas reactions, gaseous reactions, heat transfer, and geometrical changes of the solid particles and bed structure are reflected in the calculation of source terms and physical properties. Details of the model were reported in a previously published paper [7]. Simulation results show good agreement with the measurement data for temperature distribution, flue gas composition, and flame propagation speeds of the combustion zone [7].

Solid materials were considered as three solid phases of iron ore, coke, and limestone. Consideration of multiple solid phases makes it possible to investigate the effects of different fuel characteristics on the bed conditions. Other additives that were not involved in the solid-gas reactions are categorized as being part of the inert material. Each solid phase consists of solid components such as moisture, char, iron ore, $\mathrm{CaCO}_{3}$, $\mathrm{CaO}$, and inert material. Each of them has specific physical properties such as density, specific heat, and thermal conductivity. $\mathrm{O}_{2}, \mathrm{H}_{2} \mathrm{O}, \mathrm{CO}_{2}, \mathrm{CO}, \mathrm{H}_{2}$, and $\mathrm{N}_{2}$ were selected as the gas species. Devolatilization was not considered since the coal contains few volatiles $(<5 \%$ in the combustible).

\section{Effects of coke content and air supply rate}

Parameters directly affecting the combustion conditions in the sintering bed were selected, i.e., coke content and combustion air supply. Model computations and sintering pot tests were performed for various sets of coke content and air supply, as listed in Table 5. The reference case is designated Coke 3.8 and is close to the common operating conditions in a field process. Limestone used in this study contains $86 \%$ $\mathrm{CaCO}_{3}$ and $14 \%$ inert material. The cases summarized in Table 5 cover all the ranges of coke content and air supply available in a real process. Many cases in which the air inlet velocity is over the upper limit $(U=0.46 \mathrm{~m} / \mathrm{s})$ were additionally calculated to investigate the extinction limit for the air supply.

\subsection{Reference case}

Fig. 5 shows a typical mechanism of combustion propagation within a sintering bed. Calculation results of the heat balance terms for the reference case are also exhibited: solid-gas convection, radiation, solidgas reaction (drying + char combustion/gasification + limestone decomposition), and conduction, at $y=$ $0.11 \mathrm{~m}$ and $y=0.49 \mathrm{~m}$. In the initial stage of the solid-gas reaction, solid-gas convection plays an important role in drying and heating the solid particles. Char combustion (or coke combustion) begins when the temperature of the solid particles is high, but the solid-gas reaction term is slightly decreased due to 
Table 3

Scope of the model

\begin{tabular}{ll}
\hline General & 1-D unsteady \\
\hline Consideration of solid material & $\begin{array}{l}\text { Homogeneous porous media } \\
\text { Multiple solid phases } \\
\text { Governing equations }\end{array}$ \\
$\begin{array}{l}\text { Mubmodels } \\
\text { Heat transfer }\end{array}$ & $\begin{array}{l}\text { Conduction, convection (between solid and gas), radiation, heat exchange } \\
\text { between solid phases }\end{array}$ \\
Solid-gas reactions & Drying, devolatilization, char combustion and gasification \\
Gaseous reactions & CO combustion \\
Geometrical changes & Particle shrinkage by char combustion/gasification \\
& Generation of macroscopic internal pores \\
& Bed height/porosity changes \\
\hline
\end{tabular}

Table 4

Summary of governing equations

\begin{tabular}{lllll}
\hline & & $\phi$ & $\Gamma_{\mathrm{eff}}$ & $S_{\phi}$ \\
\hline Mass & Solid phase I & 1 & - & $\sum_{r_{\mathrm{s}}} \dot{M}_{\mathrm{s}, I, r_{\mathrm{s}}}$ \\
& Gas phase & 1 & - & $-\sum_{I} \sum_{r_{\mathrm{s}}} \dot{M}_{\mathrm{s}, I, r_{\mathrm{s}}}$ \\
Energy & Solid phase I & $\frac{h_{\mathrm{s}, I}}{\rho_{\mathrm{s}, I}}$ & $\frac{f_{\mathrm{v}, \mathrm{s}, I} k_{\mathrm{s}, I}}{\rho_{\mathrm{s}, I} C p_{\mathrm{s}, I}}$ & $\sum_{I} h_{\mathrm{conv}, \mathrm{g}-I} A_{\mathrm{s}, I}\left(T_{\mathrm{g}}-T_{\mathrm{s}, I}\right)+q_{\mathrm{conv}, \mathrm{s} \leftrightarrow \mathrm{s}}+q_{\mathrm{rad}}$ \\
& & & & $+\sum_{r_{\mathrm{s}}} y_{I} \dot{M}_{\mathrm{s}, I, r_{\mathrm{s}}} \Delta H_{\mathrm{r}}-\left(\sum_{r_{\mathrm{s}}} \dot{M}_{\mathrm{s}, I, r_{\mathrm{s}}}\right) C_{\mathrm{p}, I} T_{\mathrm{s}, I}$ \\
& Gas phase & $\frac{h_{\mathrm{g}}}{\rho_{\mathrm{g}}}$ & $\frac{f_{\mathrm{v}, \mathrm{g}} k_{\mathrm{g}}}{\rho_{\mathrm{g}} C p_{\mathrm{g}}}$ & $-\sum_{I} h_{\mathrm{conv}, \mathrm{g}-I} A_{\mathrm{s}, I}\left(T_{\mathrm{s}, I}-T_{\mathrm{g}}\right)$ \\
& & & $+\sum_{r_{\mathrm{s}}}\left(1-y_{I}\right) \dot{M}_{\mathrm{s}, I, r_{\mathrm{s}}} \Delta H_{r_{\mathrm{s}}}+\left(\sum_{r_{\mathrm{s}}} \dot{M}_{\mathrm{s}, I, r_{\mathrm{s}}}\right) C_{\mathrm{p}, I} T_{\mathrm{s}, I}$ \\
Component $k$ & Solid phase I & $Y_{\mathrm{s}, I, k}$ & - & $\sum_{r_{\mathrm{s}}} \dot{M}_{\mathrm{s}, I, k, r_{\mathrm{s}}}$ \\
Gas species $k$ & Gas phase & $Y_{\mathrm{g}, k}$ & - & $\sum_{r_{\mathrm{s}}} \sum_{I} \dot{M}_{\mathrm{s}, I, k, r_{\mathrm{s}}}+\sum_{r_{\mathrm{g}}} \dot{M}_{\mathrm{g}, k, r_{\mathrm{g}}}$ \\
\hline
\end{tabular}

Table 5

Experimental and calculation cases

\begin{tabular}{lllllll}
\hline Case name & Solid fuel & $U(\mathrm{~m} / \mathrm{s})$ & $\begin{array}{l}\text { Contents of } \\
\text { solid fuel } \\
\text { (mass\%, wet) }\end{array}$ & $\begin{array}{l}\text { Mean fuel } \\
\text { diameter } \\
(\mathrm{mm})\end{array}$ & $\begin{array}{l}\text { Moisture } \\
\text { contents } \\
(\mathrm{mass} \%)\end{array}$ & $\begin{array}{l}\text { Experiment/ } \\
\text { calculation }\end{array}$ \\
\hline Coke3.4 & Coke & 0.42 & 3.4 & 2.0 & 8.0 & Both \\
Coke3.8 & Coke & 0.42 & 3.8 & 2.0 & 8.0 & Both \\
Coke4.2 & Coke & 0.42 & 4.2 & 2.0 & 8.0 & Both \\
AirV0.26 & Coke & 0.26 & 3.8 & 2.0 & 7.0 & Both \\
AirV0.32 & Coke & 0.32 & 3.8 & 2.0 & 7.0 & Both \\
AirV0.42 & Coke & 0.42 & 3.8 & 2.0 & 7.0 & Both \\
AirV0.46 & Coke & 0.46 & 3.8 & 2.0 & 7.0 & Both \\
Coke100 & Coke & 0.42 & 3.7 & 2.0 & 7.0 & Calculation \\
Anth100 & Anthracite & 0.42 & 3.93 & 1.2 & 7.0 & Calculation \\
Anth1.2 & Anthracite & 0.42 & 3.93 & 1.4 & 7.0 & Calculation \\
Anth1.4 & Anthracite & 0.42 & 3.93 & 1.6 & 7.0 & Calculation \\
Anth1.6 & Anthracite & 0.42 & 3.93 & 1.8 & 7.0 & Calculation \\
Anth1.8 & Anthracite & 0.42 & 3.93 & & Calculation \\
\hline
\end{tabular}

\footnotetext{
a Coke 3.8 is a reference case.

b Anth100 is the same case as Anth2.0.
}

limestone composition, which mainly occurs in the initial stage of char combustion. After limestone decomposition is completed and the temperature of solid material becomes higher than that of the combustion gas, the solid-gas convection term falls to a negative value, indicating that the temperature of the solid material is higher than that of the gas flow. Radiation and conduction between the solid material at an objective cell and neighboring cells do not significantly affect the whole process of combustion propagation. 


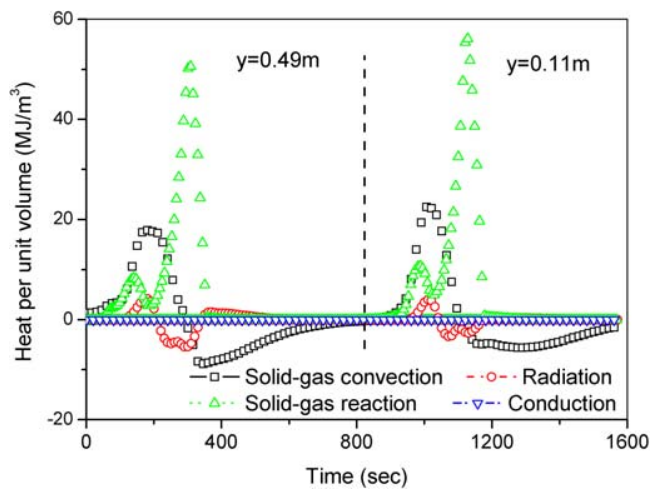

Fig. 5. Heat balance terms at $y=0.11 \mathrm{~m}$ and $y=0.49 \mathrm{~m}$.

Comparing profiles of the heat balance terms at the points $y=0.49 \mathrm{~m}$ and $y=0.11 \mathrm{~m}$, the peak values of solid-gas convection and reaction at $y=0.49 \mathrm{~m}$ are found to be higher than the values at $y=0.11 \mathrm{~m}$. These data show that the fresh air passes through a thicker and hotter sintered zone where the reactions are completed, and then contacts the fuel with higher air temperature. This causes the solid particles to be heated more rapidly and thereby accelerates the solidgas combustion at $y=0.11 \mathrm{~m}$.

The mechanism of combustion propagation in the iron ore sintering bed is somewhat different from propagation in a waste bed, as investigated numerically in a previous work [9]. In the case of the incinerator waste bed, radiation between the waste bed and hot gas/wall plays an important role in ignition and combustion propagation, while convection is important for heating and ignition of fuel particles in the case of an iron ore sintering bed. The difference arises from radiative heat input at the initial stage of the process in the waste bed. Furthermore, the radiative heat input penetrates the bed better since the solid particles inside the waste bed are much larger than those in the sintering bed; solid particles simulated for the waste bed were $10-30 \mathrm{~mm}$ in diameter [9], while the particles in the sintering bed were $1-3 \mathrm{~mm}$.

Fig. 6 shows the calculation result of CZT and MZT compared with the thickness of the hightemperature region $(>1000 \mathrm{~K})$ for the reference case. The profile of the thickness of the high-temperature region includes the MZT profiles. The MZT and the thickness of the high-temperature region, which are determined only from the temperature, tend to increase as the process continues. On the other hand, CZT shows a relatively flat trend, accounting for the increasing difference between CZT and MZT, the thickness of the high-temperature region. The gaps are due to convection cooling by inlet air in the upper part of the high-temperature zone, which implies that the combustion heat accumulates during the process. Generally, the accumulation causes additional melt-

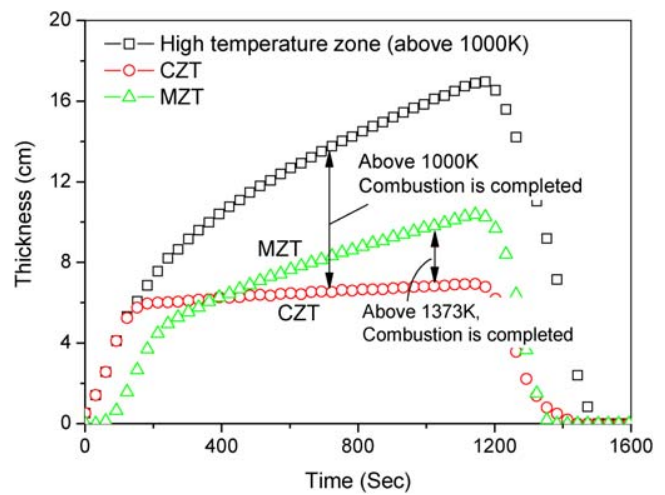

Fig. 6. Calculation results of CZT and MZT compared with the thickness of the high-temperature zone (above $1000 \mathrm{~K}$ ).

ing of iron ores, mainly in the lower part of the bed, thus decreasing bed permeability. This effect should be reflected in the model for further numerical study of the iron ore sintering process.

\subsection{Effect of coke content}

Fig. 7 shows the experimental results of temperature profiles and gas compositions for various coke contents for a fixed air supply value. For higher coke content, the high-temperature zone is shown to be broader and the peak temperature is higher, implying that combustion is apparently better sustained for higher fuel content in this condition. This is reflected in the $\mathrm{O}_{2}$ and $\mathrm{CO}_{2}$ composition in the flue gas. Higher concentration of $\mathrm{CO}_{2}$ and lower $\mathrm{O}_{2}$ concentration are found for higher coke content, which shows that the coke combustion rate increases for higher coke content. Additionally, the width of the temperature profile tends to increase for higher coke content, which indicates that DTCZ at a given location is increasing. Fig. 8 shows the calculation results of DTCZ and peak temperature for various coke contents. Increase of the DTCZ and MaxT for higher coke content is found. Additionally, the DTCZ and the MaxT are increased for the lower part of the bed. These increases are attributed to increased convection heat transfer from the gas phase and acceleration of coke combustion. At the same time, the coke combustion rate is limited by oxygen diffusion at high temperature, where, for higher coke content, the duration time is extended until the coke is completely consumed.

The results described above are supported by further calculation for the cases of various coke content and by the model-based quantification parameterscombustion zone thickness (CZT) and maximum temperature (MaxT) profiles-as shown in Fig. 9. No significant difference is found in the profiles of MaxT between 3.8 and $4.2 \%$ coke content, except for the 


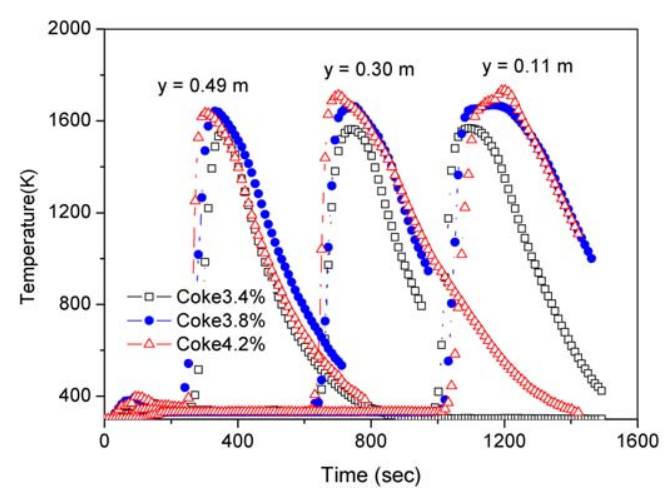

(a)

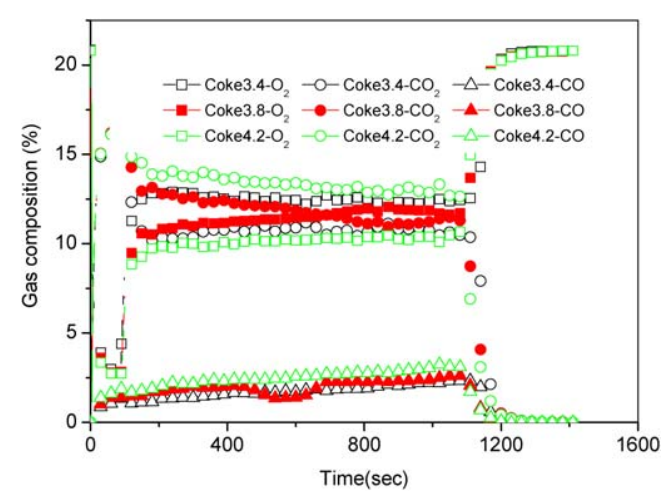

(b)

Fig. 7. Test results of temperature profiles (a) and gas compositions (b) for various coke content.

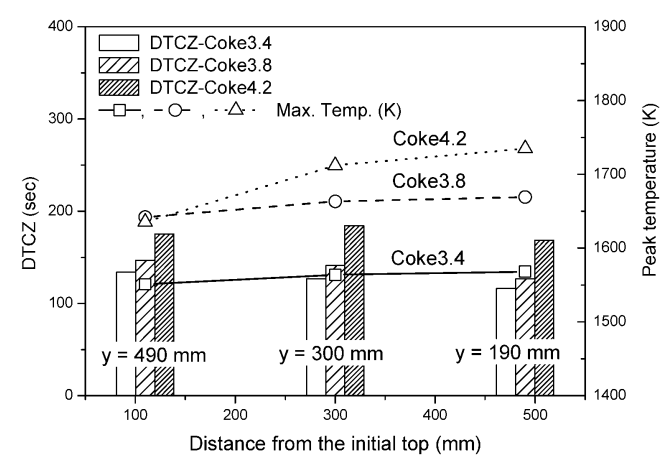

Fig. 8. Peak temperature and DTCZ for various coke content.

decreasing time of MaxT, which shows the completion time of the coke combustion. However, the MaxT values during 200-1100 s, where the MaxT profile shows a flat trend, are lowered by $\sim 50 \mathrm{~K}$ in the case of $3.4 \%$ coke content. This difference can adversely affect the quality of the product, because high temperature should be maintained to guarantee high strength of the sintered ores. Additionally, as coke content increases, the maximum temperature increases more rapidly and the completion temperature of melting is

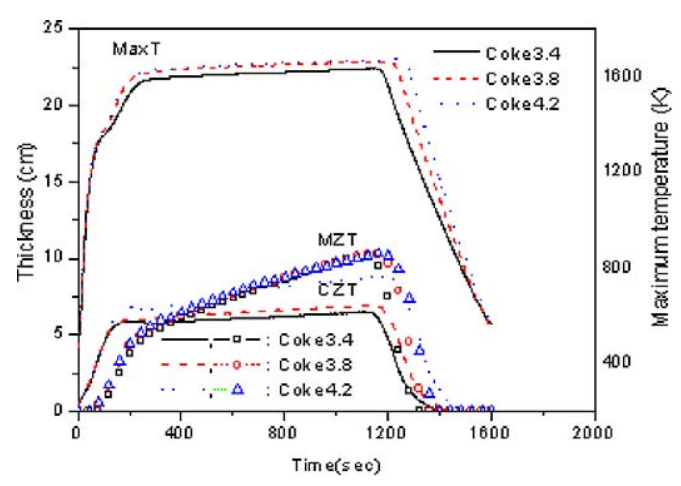

Fig. 9. Combustion zone thickness, melting zone thickness, and maximum temperature profiles for various coke content.

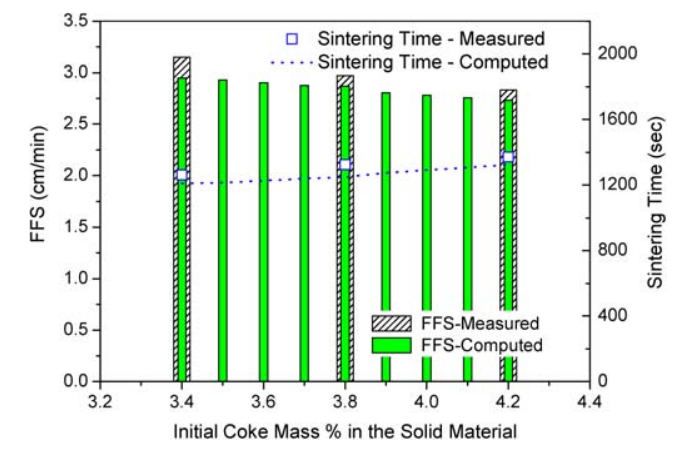

Fig. 10. FFS and sintering time for various coke content—experimental and computed results.

reached earlier. This indicates that the temperature is higher in the upper part of the bed. The coke combustion zone thickness and melting zone thickness also increase for the higher coke content.

Coke content can also influence the propagation of the combustion zone. Fig. 10 shows calculation and experimental results of FFS and sintering time for various coke contents. As coke content increases, the propagation speed of the combustion zone decreases. The sintering time for the case of $4.2 \%$ coke content is approximately $100 \mathrm{~s}$ longer than that of the case of $3.4 \%$ coke content. These results are physically reasonable because higher coke content reflects a lower air supply per unit mass of fuel, which results in lower combustion propagation speed. The calculation results show good agreement with the experimental results, thus implying that the model adequately describes combustion characteristics for various coke contents.

\subsection{Effect of air supply}

The air supply rate is represented by the average air velocity, $U$, which is set at $0.26-0.46 \mathrm{~m} / \mathrm{s}$. Basically, the amount of combustion air is determined by the initial pressure difference of the suction fan, 


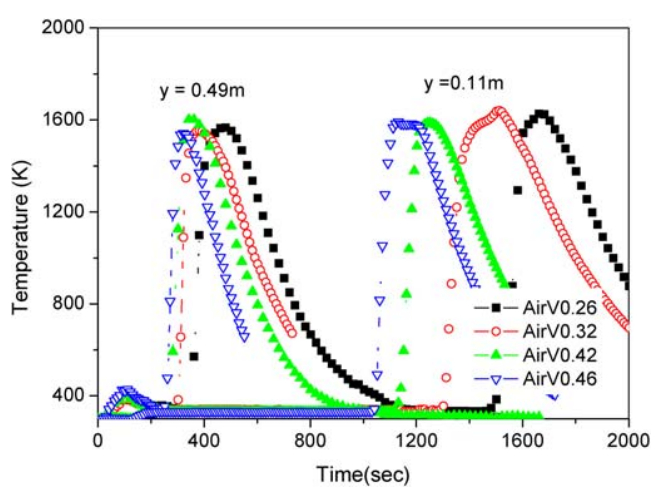

(a)

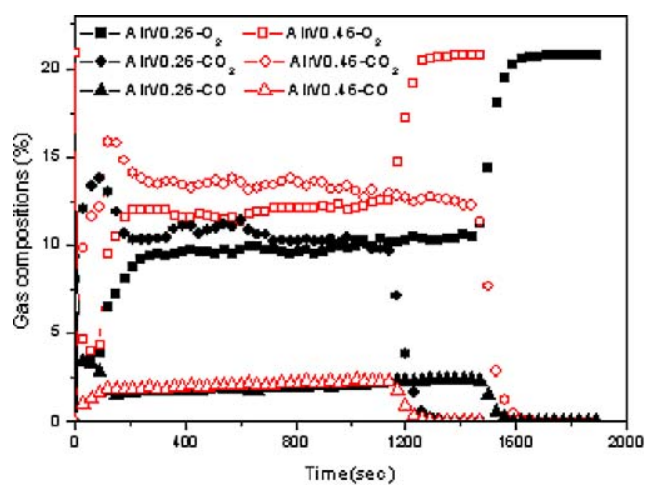

(b)

Fig. 11. Test results of temperature profiles (a) and gas compositions (b) for various air velocities.

which is set just after the end of ignition. The amount of air supply varies with time because the particle size and porosity of the bed are changing, as shown in Fig. 4. The curves of the air inlet velocities for various initial pressure differences are estimated and fitted by polynomials for model calculations.

Fig. 11 shows experimental results for temperature profile and gas composition for various air velocities. The temperature profile and gas composition are dramatically affected by the air supply, as expected. For lower air velocities, the temperature rise at a given point is significantly delayed, which implies that the combustion zone propagates more slowly through the sintering bed. From the results of flue gas composition, an increase of $\mathrm{CO}_{2}$ concentration can be found in the case of higher air velocity, and coke combustion is completed later for the lower air supply. This indicates that the fuel consumption rate is increased when the combustion propagation becomes faster at higher air velocity. Fig. 12 shows simulation and measurement results of the FFS and sintering times for various air inlet velocities. The simulation results are in close agreement with the measurement results, demonstrating that the coke combustion rate can be well estimated by this numerical model. FFS is proportionally

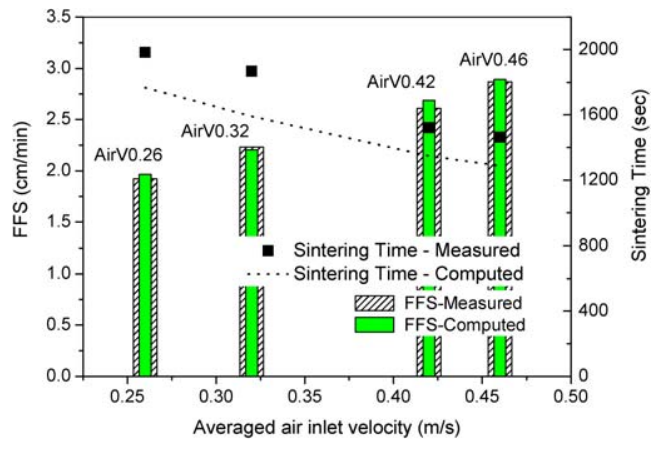

Fig. 12. FFS and sintering time for various air velocities-experimental and computed results.

increased along with the air inlet velocity, while the sintering time shows an opposite trend. These parameters are directly related to the productivity of the sintered ore. Specifically, a high rate of air supply accelerates FFS, and then sintering time can be reduced; i.e., the time for the whole process can be saved, and thus productivity can be improved. However, a high rate of air supply requires more fan power and greater capacities of the flue gas treatment system, which requires careful $\Delta P$ setting of the suction fan.

Fig. 13a shows the calculated DTCZs at three points for various air velocities. The profiles of the DTCZs have different trends for each location within the bed. At $y=0.49 \mathrm{~m}$, which represents the upper part of the bed, the DTCZ values are rapidly decreased in the velocity range of $0.2-0.4 \mathrm{~m} / \mathrm{s}$, while the profiles for $y=0.30 \mathrm{~m}$ and $y=0.11 \mathrm{~m}$ are less dramatically changed. When the air supply is small, coke particles in the upper part of the bed required a longer time to burn out. The lower part of the bed is not significantly affected by the change in air supply. DTCZ profiles show a decreasing trend as the air supply is increased, which indicates that the coke combustion rate at a given point is accelerated with a larger amount of air. When the average air velocity is over $1.0 \mathrm{~m} / \mathrm{s}$, the DTCZ value for $y=0.49 \mathrm{~m}$ is rapidly decreased, which means that the convection heat loss between the solid particles and the cold air is greater than the heat input from the combustion front. At $U=1.06 \mathrm{~m} / \mathrm{s}$, coke combustion cannot be sustained any longer, and the flame becomes extinct. Fig. 13b shows the FFSs for air velocities. The relationship between combustion propagation and air supply is known to be proportional when the combustion is limited by oxygen (Regime 1). However, if more air is supplied, combustion propagation is limited by convection cooling (Regime 2). In that regime, FFS tends to be constant or decreased even if the air supply is increased. Over a limited air supply, combustion cannot be sustained and is extinguished when the convection cooling exceeds the amount of combustion 


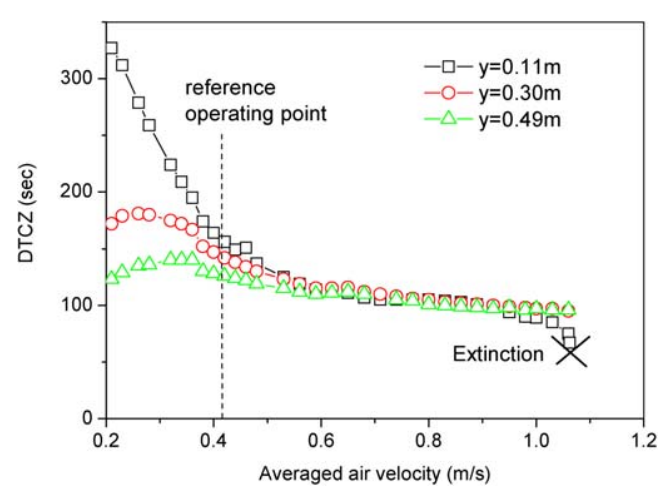

(a)

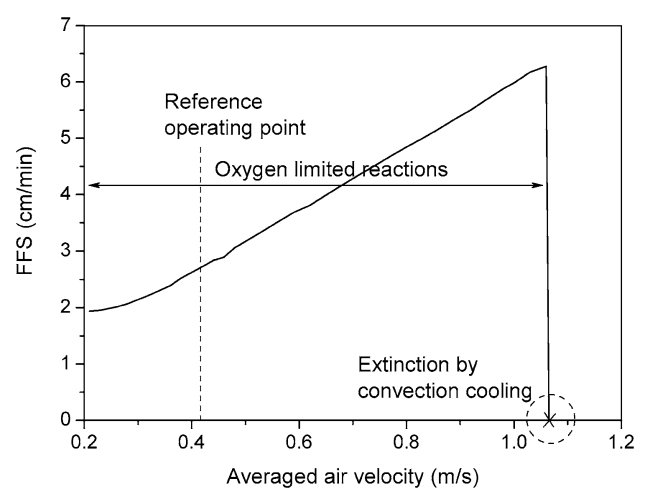

(b)

Fig. 13. Computed results of DTCZs (a) and FFSs (b) for various air velocities.

heat (Regime 3). Previous simulation results [9] for a fixed bed of wood cubes in a radiative environment show these regimes clearly. However, the FFS curve shown in Fig. 13b does not show the characteristics of Regime 2, which are caused by the difference of particle diameter between the fixed bed (typically $20 \mathrm{~mm}$ in diameter) and the iron ore sintering bed (typically 2-3 mm in diameter). Previous research [9] shows that the range of air supply for Regime 2 becomes broader when the particle size of the fuel is increased. When the particle size is increased, the total surface area is decreased. The convection cooling effect should then be decreased, which means that combustion can be better maintained for a higher air supply. In the case of an iron ore sintering bed, the range of Regime 2 does not exist due to the small particle size.

Fig. 14 shows the heat balance terms at $y=0.49 \mathrm{~m}$ and $y=0.30 \mathrm{~m}$ under extinction conditions of $U=$ $1.06 \mathrm{~m} / \mathrm{s}$. The level of combustion heat at $y=0.49 \mathrm{~m}$ is not high compared with the convective heat transfer, which means that the combustion heat is not sufficient to propagate the combustion process downward. In the extinction conditions caused by excessive air, the gas temperature is not high due to convec-

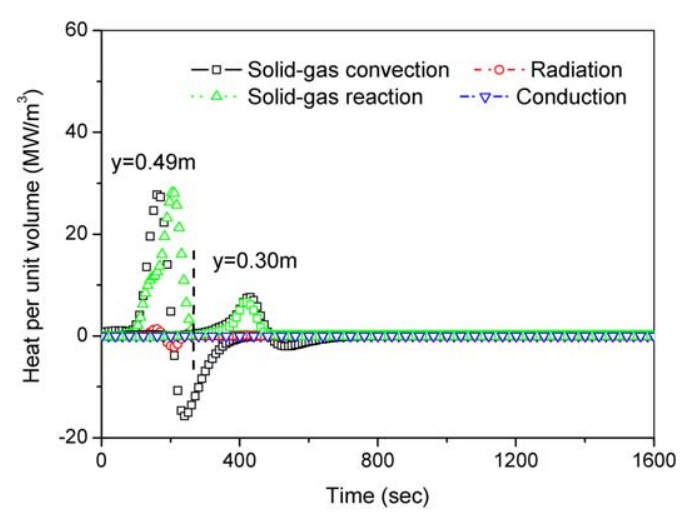

Fig. 14. Heat balance terms at $y=0.49 \mathrm{~m}$ and $y=0.30 \mathrm{~m}$ under extinction conditions $(U=1.06 \mathrm{~m} / \mathrm{s})$.

tion cooling and also because the convective heat input from the gas flow is not sufficient to heat fuel particles up to a temperature of initiating char combustion. Consequently, combustion heat generated at $y=0.30 \mathrm{~m}$ is dramatically decreased, as shown in Fig. 14. From these results, it can be seen that ignition conditions and combustion characteristics of the upper part of the bed (that is, the initial stage of the process after ignition) affect the whole process significantly, especially for the features related to selfsustaining combustion.

Fig. 15 shows the details of the phenomena described above, using CZT and MaxT. While the air velocity affects the flame front speed and sintering time significantly, combustion zone thickness and melting zone thickness do not show considerable differences for various air suction rates, except that the times for the profiles to fall to zero reflect the different propagation speeds of the combustion front and sintering time. These results show that a greater air supply can improve productivity without compromising the quality of the sintered ores. However, an increased air supply rate results in a higher amount of combustion gas and thereby requires a larger flue gas treatment system.

From the case studies related with air/fuel ratio, it can be seen that the newly defined quantitative parameters can effectively describe the combustion characteristics in a solid fuel bed as well as the effects of the major operating parameters.

\section{Fuel substitution: coal for coke}

The study described in this section focuses on obtaining basic results in the process of setting adequate operating conditions for using anthracite as a substitution fuel. The anthracite used in this study is from China and is employed in commercial iron ore sinter- 


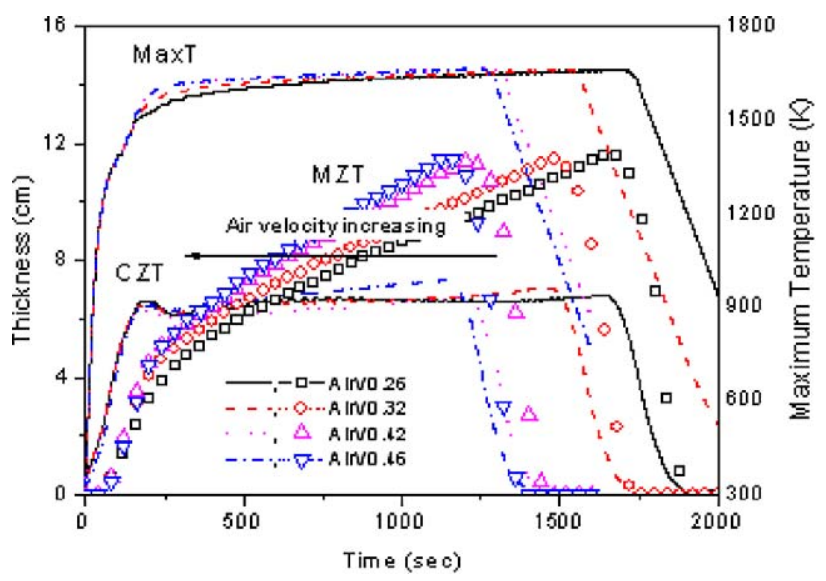

Fig. 15. Combustion zone thickness, melting zone thickness, and maximum temperature profiles for various air velocities.

Table 6

Results of elemental and proximate analysis for coke and anthracite

\begin{tabular}{lll}
\hline & Coke & Anthracite \\
\hline Elemental analysis $(\%)$ & & \\
$\mathrm{C}$ & 87.86 & 86.04 \\
$\mathrm{H}$ & 0.63 & 1.34 \\
$\mathrm{O}$ & 9.42 & 11.85 \\
$\mathrm{~N}$ & 1.55 & 0.56 \\
$\mathrm{~S}$ & 0.54 & 0.21 \\
Proximate analysis $(\%$, dry base) & & \\
Volatile & 2.26 & 4.99 \\
$\quad$ Fixed carbon & 83.75 & 79.69 \\
Ash & 13.99 & 15.32 \\
Heating value $(\mathrm{kJ} / \mathrm{kg})$ & 26352 & 24999 \\
\hline
\end{tabular}

ing processes in Korea. Table 6 shows the results of a basic analysis for the characterization of the fuel, including an elemental analysis, proximate analysis, and calorimetric analysis. The anthracite employed in this study contains $\sim 5 \%$ volatiles. Coke contains more fixed carbon and less ash content than anthracite, which makes the heating value of coke higher than that of anthracite. The ratio of fixed carbon in the coke and in anthracite corresponds with the ratio of the heating values of coke and of anthracite.

A thermogravimetric analysis was carried out to investigate the difference of reactivity of coke and anthracite. Test apparatus was built in house for a relatively large sample, typically on the order of $1 \mathrm{~g}$. The heating rate was set to $10^{\circ} \mathrm{C} / \mathrm{min}$ from room temperature to $1000^{\circ} \mathrm{C}$ and was maintained constant thereafter. Nitrogen was used as a carrier gas for constant temperature under $1000^{\circ} \mathrm{C}$, while air was used for constant temperature of $1000^{\circ} \mathrm{C}$. Flow rate of the carrier gases was set to $101 / \mathrm{min}$. Fig. 16 presents the results of the thermogravimetric analysis for coke and anthracite in the char oxidation environment. The thermogravimetric curves show that the mass reduction of coke by char combustion is faster than that of anthracite. From the differential thermogravimetric curves for the two kinds of fuel, a meaningful difference of char reactivity can be found. The reactivity of anthracite is lower than that of coke, which can affect the combustion conditions in the sintering bed. The difference of reactivity is attributed to the difference of true surface area as well as intrinsic surface reactivity [19]. As shown in Fig. 17, coke has many internal pores, while the pores of the anthracite used in this study were not distinctively found. Examination of the quantitative relationship between the pore sizes and the true surface area is beyond the scope of this study. The influence of the different fuel characteristics on the combustion conditions in the sintering bed was investigated in this model study. In the test, the initial mass fraction of anthracite was set to $3.93 \%$ based on the content of fixed carbon. The difference of internal pores of the two fuels is reflected in the solid property model for density, specific heat, and surface area. The initial values of the volume fraction of internal pores are set to 0.1 for the anthracite and 0.45 for the coke. These values are derived from the measurement values of the apparent densities for the coke and the anthracite.

Fig. 18 shows the calculation results of the heat balance terms for Anth100. The difference of fuel reactivity is well shown in the profile of the solid-gas reaction term, compared with the profile in Fig. 5. Both at $y=0.49 \mathrm{~m}$ and $y=0.11 \mathrm{~m}$, the peak values of the solid-gas reaction heat in the case of Anth100 are lower but the reaction time is longer. These features reflect the difference of reactivity between coke and anthracite. In Anth100, compared with Coke100, the combustion propagation is retarded due to slow generation of combustion heat. As shown in Table 7, 


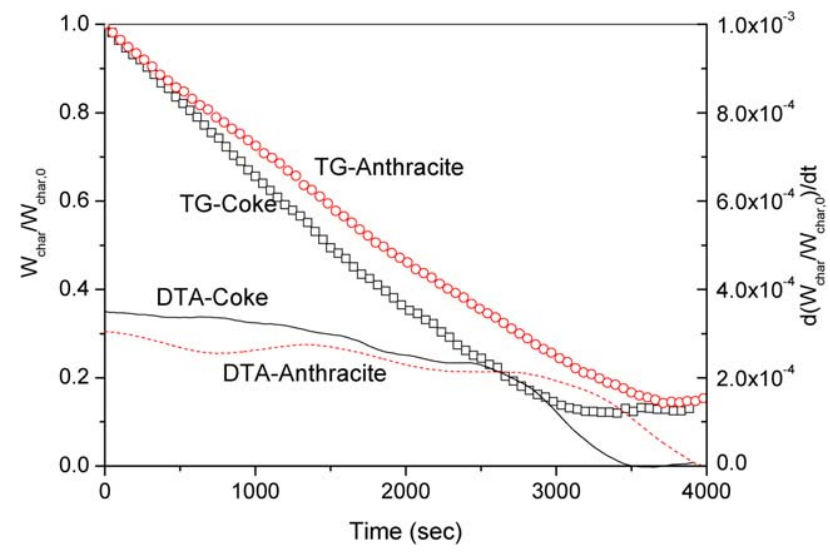

Fig. 16. Results of thermogravimetric analysis for coke and anthracite.

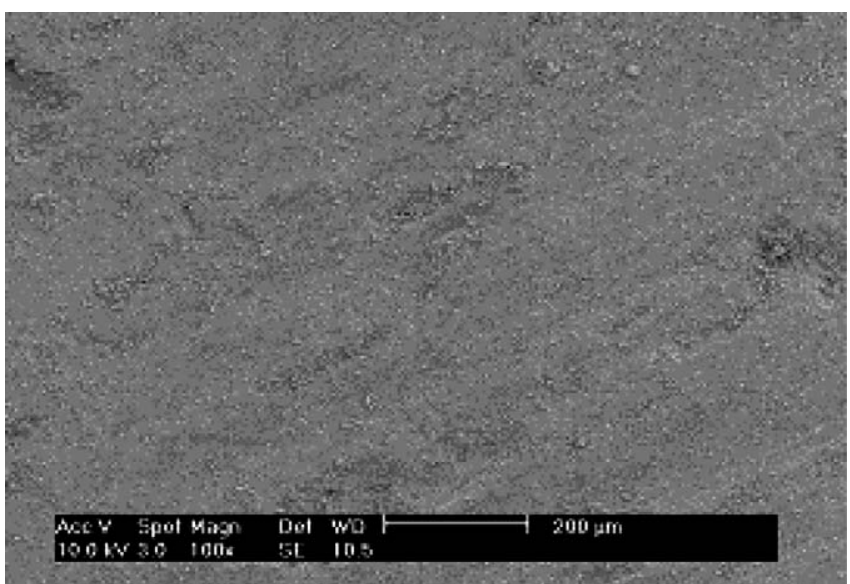

(a)

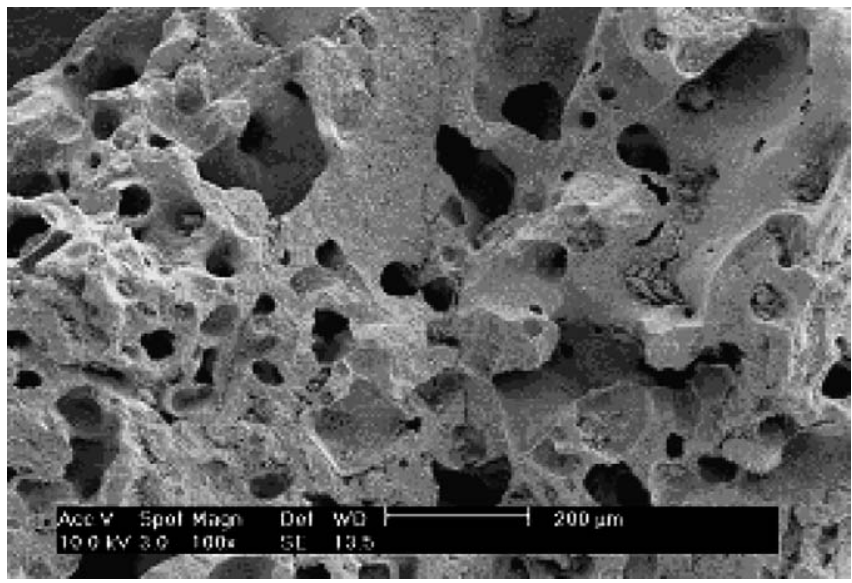

(b)

Fig. 17. SEM photograph of the anthracite (a) and coke (b).

FFS and sintering time represent the difference in fuel, which can significantly affect the productivity. Fig. 19a shows the temperature profiles in the upper part $(y=0.49 \mathrm{~m})$ and the lower part $(y=0.11 \mathrm{~m})$ of the bed, and a delay of temperature rise at $y=$ $0.11 \mathrm{~m}$ in case of Anth100 appears. Another feature 


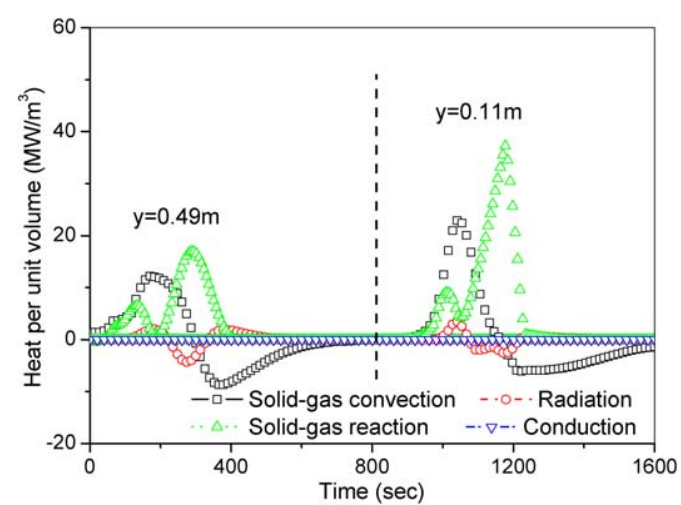

Fig. 18. Heat balance terms at $y=0.49 \mathrm{~m}$ and $y=0.11 \mathrm{~m}$ for coke and anthracite.

for Anth100 shown in the MaxT profile in Fig. 19a is lower MaxT in the time range of 100-400 s. This implies that the maximum temperature of the region near the top of the bed is considerably low. This indicates the possibility of not obtaining sufficiently high temperature for the melting of the iron ores near the top of
Table 7

FFS and sintering time for Coke100 and Anth100

\begin{tabular}{lll}
\hline Case name & FFS $(\mathrm{cm} / \mathrm{min})$ & Sintering time $(\mathrm{s})$ \\
\hline Coke100 & 2.98 & 1210 \\
Anth100 & 2.76 & 1296 \\
\hline
\end{tabular}

the bed, in which case the quality of the sintered ores would likely be deteriorated. Meanwhile, the lower combustion rate of the anthracite results in a different CZT profile, as shown in Fig. 19b. CZT values for Anth100 are lower than those for Coke100 during the early stage of the process $(t=100-300 \mathrm{~s})$, since the effect of convection heat loss by air is increased and the combustion rate is lower. During the later stage of the process, however, the combustion zone becomes broader. However, MZT values for Coke100 are larger than those for Anth100. This appears to be related to the convective cooling effect; a greater amount of air is introduced when anthracite combustion is completed, because the completion time is delayed compared to the case of Coke100. Moreover, the melting zone does not appear during the earlier

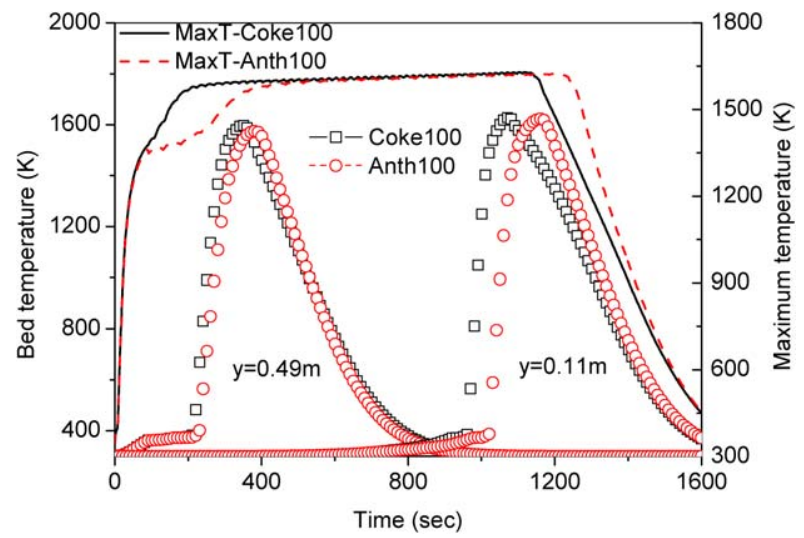

(a)

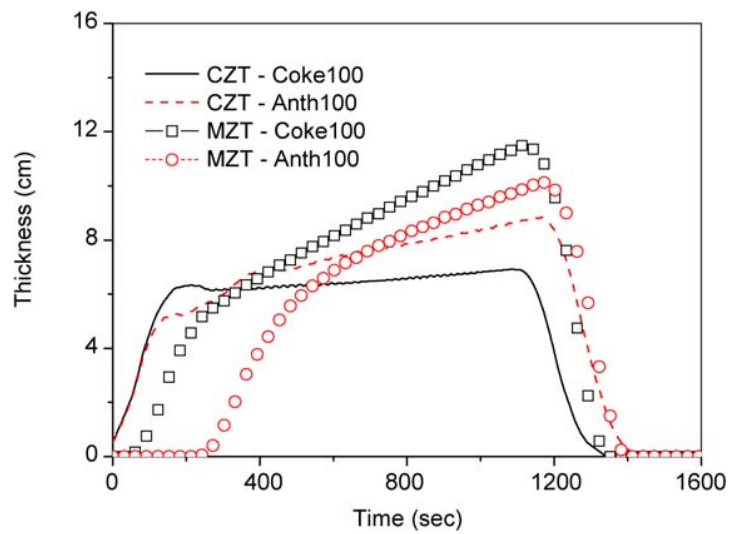

(b)

Fig. 19. Calculation results for coke and anthracite: (a) temperature profiles, (b) CZT and MZTs. 


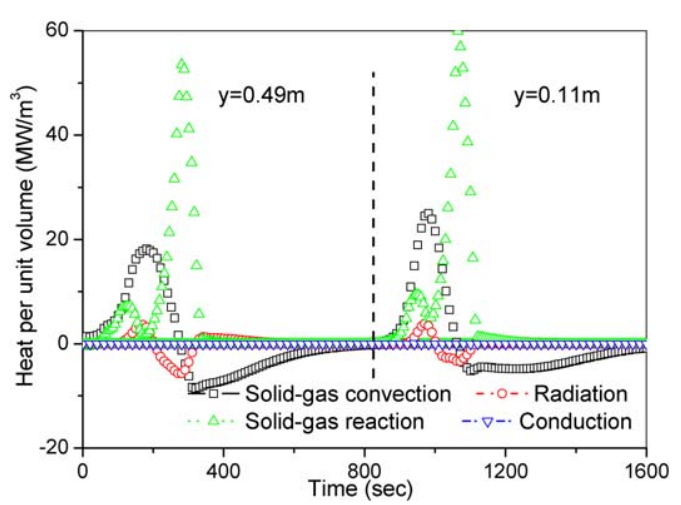

Fig. 20. Heat balance terms at $y=0.49 \mathrm{~m}$ and $y=0.11 \mathrm{~m}$ for Anth1.2.

stage of the process for Anth100, suggesting a possibility of deficiency in forming sintered ores in the upper part of the bed. Considering that the values of MaxT for Anth100 are not larger than those for Coke100, thermal concentration appears to be unfavorable for Anth100. In conclusion, the combustion characteristics of anthracite as a substitution fuel are not as favorable as coke for the sintering process.

However, the low reactivity of the anthracite can be improved by decreasing the particle size and thus by increasing the volumetric surface area. In the char reaction model used in this study, the char combustion rate is increased proportionally with the apparent surface area of the char particles. Fig. 20 shows the profiles of the heat balance terms for Anth1.2. The profiles of solid-gas reactions become similar to those of Coke100 (Coke3.8) in Fig. 5 while the profiles at $y=0.11 \mathrm{~m}$ are advanced, which means that combustion propagation becomes faster. This is also shown in Fig. 21a, which shows that points where temperature is rising are meaningfully advanced when smaller particles of anthracite are used. Fig. 21a also shows the MaxT profile for various diameters of anthracite (1.2, 1.6 , and $2.0 \mathrm{~mm}$ ) and its values in the time range of $100-400 \mathrm{~s}$ are increased. From these results, it can be seen that the productivity and quality of the sintered ores can be improved by using smaller particles of anthracite. The thickness profiles (Fig. 21b) for various diameters of anthracite $(1.2,1.6$, and $2.0 \mathrm{~mm}$ ) also show that the CZT can be decreased to a level corresponding to the use of coke by reducing the anthracite particle size. This trend is similarly observed when a highly reactive fuel is used, which implies that the difference in fuel reactivity can be overcome by controlling the particle size of the fuel.

FFS and sintering time for the cases of various particle sizes are shown in Fig. 22. Sintering time is shown to be shortened by approximately $100 \mathrm{~s}$ when the particle sizes of the anthracite are reduced from 2.0 to $1.2 \mathrm{~mm}$. This indicates the possibility of main- taining the same level of productivity when a portion of coke is replaced by anthracite by reducing the size of the particles.

\section{Conclusion}

A quantitative description of combustion characteristics in an iron ore sintering process is presented, based on sintering pot tests and a mathematical model of solid bed combustion. Characterization of the bed combustion is attempted through the introduction of newly defined parameters: duration time in the combustion zone (DTCZ), combustion zone thickness (CZT), melting zone thickness (MZT), and maximum temperature (MaxT). Flame front speed (FFS) and sintering time (ST), well-known parameters for describing the propagation of solid fuel combustion in a fixed bed, are also assessed. They can be obtained by the mathematical model and sintering pot test. These parameters can represent the effects of the two factors dominating solid bed combustion: operating conditions relating to combustion and intrinsic fuel properties. The effects of operating parameters-coke contents in the bed material and air supply rateon the combustion characteristics and the quantitative parameters are investigated. It is found that fixed-bed combustion can be well characterized by the quantified parameters based on distributions of solid temperature and mass fraction of the char content in the bed. Effects of the intrinsic fuel properties are investigated numerically for fuel substitution from coke to anthracite and various particle sizes of anthracite. The following conclusion can be derived from this study.

1. The dominating mode of heat transfer within an iron ore sintering bed is convection between gas flow and solid material. Raw fuel is heated mainly by convection in the initial stage, and char (or coke) combustion after the fuel is heated to the ignition temperature. The combustion rate of the fuel determines the combustion propagation speed and the characteristics of the combustion zone such as thickness and temperature. The effect of radiation is not as significant with respect to the combustion process, in contrast to a fixed bed of wood cubes of large particle size ignited by radiation.

2. Values of FFS and ST show the effect of air supply on the whole combustion process. Because of the small particle sizes in the iron ore sintering bed, there was no region where the combustion propagation speed was not affected by air supply. FFS profiles show that combustion cannot be sustained due to excessive convection cooling when air supply exceeds a limiting point. In particular, the combustion conditions in the upper part of the bed (upstream of the gas flow) are very sensitive to the operating conditions, 


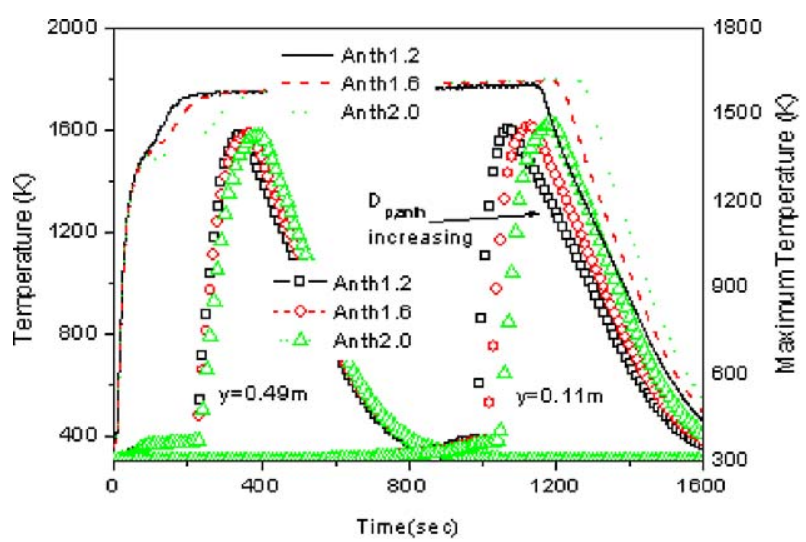

(a)



(b)

Fig. 21. Calculation results for various diameters of anthracite: (a) temperature profiles, (b) CZT and MZTs.

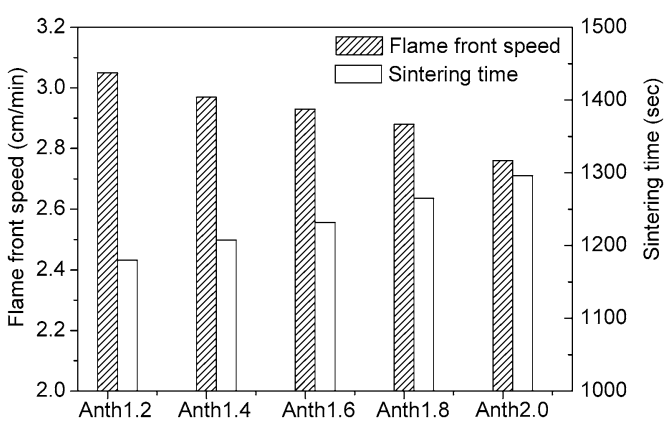

Fig. 22. FFS and sintering time for various particle sizes of anthracite.

while those in the lower part of the bed are not sensitive due to heat accumulation.

3. Values of CZT, MZT, DTCZ, and MaxT reflect the effects of parameters related to fuel content and characteristics. Since the quantitative parameters should be carefully controlled for the quality of the product, selection of fuel and its content is crucial to effective operation. The approach presented here can provide quantitative criteria.
4. The effect of fuel reactivity is seen in the propagation speed of the combustion front and the temperature in the upper part of the bed, which were reflected in the results of FFS, ST, and MaxT. The anthracite showed slower FFS and lower temperature in the upper part of the sintering bed, which would adversely affect the productivity and quality of the sintered ores. CZT values in the lower part of the bed were significantly increased due to the longer combustion time for anthracite. Case studies for various particle sizes of anthracite, however, show that the combustion rate can be improved by decreasing the particle size.

\section{Acknowledgments}

This study has been financially supported by POSCO and an international collaborative research program funded by the Korea Ministry of Science and Technology. The authors also acknowledge support from the Combustion Engineering Research Center (CERC). 


\section{References}

[1] I. Muchi, J. Higuchi, Testu-to-Hagane 56 (1970) 371381.

[2] R.W. Young, Ironmak. Steelmak. 7 (1977) 321-328.

[3] M.J. Cumming, J.A. Thurlby, Ironmak. Steelmak. 17 (1990) 245-254.

[4] F. Patisson, J.P. Bellot, D. Ablitzer, E. Marliere, C. Dulcy, J.M. Steiler, Ironmak. Steelmak. 18 (1991) 8995.

[5] N. Nath, J. Da Silva, N. Chakraborti, Steel Res. 68 (1997) 285-292.

[6] M.V. Ramos, E. Kasai, J. Kano, T. Nakamura, ISIJ Int. 40 (2000) 448-454.

[7] W. Yang, C. Ryu, S. Choi, ISIJ Int. 44 (2004) 492-499.

[8] Y.R. Goh, R.G. Siddall, V. Nasserzaheh, R. Zakaria, J. Swithenbank, D. Lawrence, N. Garrod, B. Jones, J. Inst. Energy 71 (1998) 110-118.
[9] D. Shin, S. Choi, Combust. Flame 121 (2002) 167-180.

[10] C. Ryu, D. Shin, S. Choi, J. Air Waste Manage. 52 (2002) 189-197.

[11] B. Peters, Combust. Flame 131 (2002) 132-146.

[12] M.L. Hobbs, P.T. Radulovic, L.D. Smoot, AIChE J. 38 (1992) 681-702.

[13] P.T. Radulovic, M.U. Ghani, L.D. Smoot, Fuel 74 (1995) 582-594.

[14] M.U. Ghani, T. Predrag, P.T. Radulovic, L.D. Smoot, Fuel 75 (1996) 1213-1226.

[15] C.D. Blasi, Chem. Eng. Sci. 55 (2000) 2931-2944.

[16] A. Galgano, C.D. Blasi, Combust. Flame 139 (2004) 16-27.

[17] J. Cooper, W.L.H. Hallett, Chem. Eng. Sci. 55 (2000) 4451-4460.

[18] J.C. Wurzenberger, S.W. Wallner, H. Raupenstrauch, J.G. Khinast, AIChE J. 48 (2002) 2398-2411.

[19] I.W. Smith, Proc. Combust. Inst. 19 (1982) 1045-1065. 